\title{
Onde a Língua Portuguesa é falada: início de uma
} conversa.

\author{
Where Portuguese Language is talked: beginning of \\ dialogue.
}

\section{Où la langue portugaise est parlée : un début de conversation.}

Marina Dias AMORIM

\section{RESUMO}

Este depoimento tem como objetivo explicitar o planejamento de uma intervenção didátíca, cujo tema é a Língua Portuguesa e os locais onde ela é usada como língua oficial. Além disso, visa expor inquietações a respeito da realização de um trabalho que pretenda aproximar alunos do Ensino Fundamental II e as culturas dos países lusófonos.

Palavras-chave: Língua Portuguesa; países lusófonos; planejamento de atividades.

\section{ABSTRACT}

This report aims to describe the planning of a didactic intervention, whose subject is the Portuguese Language and the places where it is used as official language. Moreover, it intends to at show some unrest about approaching pupils of Basic School second term and the cultures of the Lusophone countries.

Index terms: Portuguese language; Lusophone countries; planning of activities.

\section{RESUME:}

Ce témoignage a comme objectif démontrer la planification d'une intervention didactique, dont le sujet est la Langue Portugaise et les lieux où elle est utilisée comme langue officielle. Ainsi, il vise à exposer des inquiétudes 
concernant à la réalisation d'un travail que sert á approcher les élèves du secondaire et les cultures des pays lusophones.

Mots clés: Langue Portugaise; pays lusophones; planification d'activités.

O presente depoimento refere-se à transposição didática realizada a partir da proposta de "espaço de criação" da qual participei durante o primeiro semestre de 2008 .

De acordo com o planejamento feito, as atividades seriam realizadas em uma EMEFM ${ }^{1}$ localizada na zona norte de São Paulo — onde atuo como professora eventual de Ensino Fundamental II há quase três meses. Tal escola enfrenta problemas variados, muitos dos quais relacionados à indisciplina, como o alto índice de agressão entre os estudantes, depredação e desrespeito aos professores. Assim, até por esse perfil, ela foi escolhida como local de intervenção, uma vez que o tema possibilitaria o trabalho transversal com as questões de pluralidade cultural e tolerância.

O assunto a ser explorado com os alunos era 'onde a Língua Portuguesa é falada', considerando também a questão da origem desse idioma.

A turma escolhida para a transposição didática foi uma classe de $6^{\mathrm{a}}$ série com aproximadamente 40 alunos que manifestam um relativo envolvimento com as questões apresentadas, o que, de acordo com minha hipótese, poderiam ser ampliadas.

Foram traçados como objetivos específicos da intervenção: aprofundar o conhecimento sobre a história da língua portuguesa; conceituar lusofonia e conhecer um pouco sobre os países lusófonos, verificando os pontos em que se aproximam; valorizar as diferentes culturas e variedades lingüísticas.

\footnotetext{
${ }^{1} \mathrm{O}$ nome da escola foi omitido para que não pudesse ser identificada.
} 
Como práticas a serem realizadas em aproximadamente dez aulas, planejei:

- apresentar a origem latina do português;

- fazer um levantamento dos conhecimentos prévios dos alunos, esperando que eles reconhecessem que o português não é idioma oficial unicamente do Brasil; supondo que eles não saberiam que ele também não se restringe a Brasil e Portugal;

- conceituar lusofonia;

- localizar no mapa os países lusófonos;

- apresentar os conceitos de língua materna e língua oficial, frisando as diferenças entre eles e exemplificando-as;

- realizar pesquisas sobre alguns desses países — relacionadas a aspectos sócio-culturais;

- levar fotografias, músicas e textos africanos de língua portuguesa — sobretudo de Angola;

- realizar debates e propor atividades (como ilustrações ou dramatizações) sobre os textos.

Tanto as pesquisas, quanto o contato com produções culturais africanas pareceram-me capazes de motivar os estudantes, uma vez que despertam a curiosidade e o interesse dos alunos e se tratam de países menos conhecidos. Além disso, um trabalho desse gênero seria produtivo e enriquecedor até para a aprendizagem de outras disciplinas, já que envolve conhecimentos de outras áreas que não só a de Língua Portuguesa.

Enfim, o planejamento da transposição didática possibilitou que fossem criadas várias expectativas. Contudo, pelo menos por enquanto, tal planejamento não foi colocado em prática. Ainda não consegui realizar a intervenção. Isto porque, para a maior parte das aulas, em que atuei como 
professora substituta, atividades didáticas já estavam programadas ou o tema não se encaixava com a disciplina (como Educação Física, Matemática e Ciências). Além do mais, talvez o fato de eu ser professora eventual, com pouco tempo de trabalho na escola, influencie na expectativa e atenção que os alunos depositam sobre minha atuação, o que fez com que fosse necessário outro tipo de abordagem, mais ligado ao estreitamento de nossas relações e a criação de um ambiente de trabalho mais acolhedor.

Agora, em meados de junho, questiono-me, no entanto, se a turma escolhida por mim é de fato a mais adequada e se eu não deveria reelaborar o plano de intervenção para partir de uma questão mais concreta. Entretanto, pretendo efetivar a transposição didática posteriormente. Assim diz o ditado: Antes tarde do que nunca.

\section{Autora:}

Marina Dias Amorim

Licenciada em Letras- Português, professora da rede municipal de São Paulo, Graduanda em Pedagogia pela FEUSP.

Contato:madamorim@uol.com.br

\section{Como citar este depoimento:}

AMORIM, Marina Dias. Onde a Língua Portuguesa é falada: início de uma conversa. Revista ACOALFAplp: Acolhendo a Alfabetização nos Países de Língua portuguesa, São Paulo, ano 4, n. 7, 2009. Disponível em: <http://www.acoalfaplp.net>. Publicado em: setembro 2009.

Recebido em junho de 2008. $\quad$ Aprovado em julho de 2008.

Sede da Edição: Faculdade de Educação da Universidade de São Paulo - Av. da Universidade, 308 - Bloco A, sala 111 - São Paulo - SP Brasil - CEP 05508-040. Grupo de pesquisa: Acolhendo Alunos em situação de exclusão social e escolar: o papel da instituição escolar.

Parceria: Centro de Recursos em Educação Não-Formal de Jovens e Adultos - CRENF - FacEd - UEM - Prédio da Faculdade de Letras e Ciências Sociais - Segundo Piso - Gabinete 303 - Campus Universitário Maputo, Moçambique, África 